\title{
Prevalence of HCV in patients suffering from various malignant disorder in Tertiary Cancer Care Center in Malwa region of Punjab
}

\author{
Deepak Arora ${ }^{1}$, M K Mahajan², Manjit Kaur ${ }^{3}$, Parvinder Singh ${ }^{4}$ \\ ${ }^{\mathbf{1}, 2}$ Professor, ${ }^{1}$ Dept. of Microbiology, ${ }^{2}$ Dept. of Radiation Oncology, ${ }^{3}$ Associate Professor, Dept. of Pathology, ${ }^{4}$ Assistant \\ Professor, Dept. of Surgical Oncology, ${ }^{1,3,4}$ Baba Farid University of Health Sciences, Faridkot, Punjab, ${ }^{2}$ Advanced Cancer \\ Institute, Bathinda, Punjab, India
}

*Corresponding Author:

Email: drdeepakarora78@gmail.com

\begin{abstract}
Hepatitis $\mathrm{C}$ virus (HCV) infection results in persistent liver disease, cirrhosis and hepatocellular carcinoma. Significant association has been seen between $\mathrm{HCV}$ and cancer .Prevalence of $\mathrm{HCV}$ infection in cancer patients range from $1.5 \%$ to $32 \%$. Aim of our study: To evaluate the Sero prevalence of hepatitis $C$ among patients with malignancy reported at ACI, Bathinda. Materials and Methods: The study was done in Advanced cancer hospital in Bathinda for a period of 1 year \& 6 months from 1.5.16 to 31.10.17. All the specimens were screened using immune chromatographic assays. The data was statistically analysed. Results: Positivity of HCV in cancer patients in our Cancer hospital was $6.6 \%$ In our cancer patients HCV was found to be more prevalent in females $(6.6 \%)$ as compared to males $(6.4 \%) .100 \%$ of cases which were reported from rural background. In males the risks for the cancers of the upper digestive tract, mandible, neck, oesophagus, and lung were higher. Tobacco exposure and alcohol use explain increase in risk. Of the 21 cases of females 12 cases of carcinoma breast, 2 Endometrial carcinoma, 1 liver carcinoma ,2 ovarian carcinoma, 1esophagal carcinoma \& 2 kidney carcinoma were reported.

Maximum number of cases were in age group of 41-70 with 28 cases in age group of 50-60 years. One patient was reported HCV positive at 94 yrs.

Conclusion: Prevalence of HCV is high in cancer. Maximum number of patients are from rural background. These patients are apprehensive to report to hospital and get examined. So, the message is very clear that either medical services in our rural areas need to be strengthened and practitioners sitting in rural population need to be educated or to look to traditional Indian medicines to which these rural population have faith like preventive aspects with the strengthening of AYUSH systems. As maximum number of cases are in females and with carcinoma of breast suggest the urgent need to educate females regarding healthy sexual practices \&lifestyle modifications.
\end{abstract}

Keywords: Flaviviridae, Immune suppression, Malignancy.

\section{Introduction}

Hepatitis $\mathrm{C}$ virus (HCV) is a RNA virus posing a global health challenge resulting in persistent liver disease, cirrhosis and Hepatocellular carcinoma. The global prevalence of $\mathrm{HCV}$ is around $2 \%$. worldwide, 170 million people are affected with $\mathrm{HCV}$ and 3 to 4 million persons are getting newly infected each year (Shepard et al 2005). ${ }^{1}$ Overall, prevalence of hepatitis $\mathrm{C}$ in India is $1 \%$, is high in Punjab ranging between $3.5 \%$ to $7 \% .^{2}$ Significant association has been seen between HCV and cancer. Risk of cancer increases in patients with Hepatitis $\mathrm{C}$ virus infection and also in turn cancer add extra ordinary challenges to the management \&treatment of $\mathrm{HCV}$. Although risk of cancer \& $\mathrm{HCV}$ infection is known but the molecular mechanisms involved in cancer signalling are unknown. $\mathrm{HCV}$ alters the cellular homeostasis by causing increase in generation of free radicals causing chronic inflammation finally leading to cancer. Prevalence of $\mathrm{HCV}$ infection in cancer patients range from $1.5 \%$ to $32 \% \%^{3-6}$ and for detection of HCV in laboratory is only based on estimation of antibodies to recombinant $\mathrm{HCV}$ proteins. Moreover HCV follows heterogenous genome and replication pathways. HCV infection is common in cancer patients and data about infection outcome is limited and not very clear. So, the present study was done to know the Sero prevalence of hepatitis $\mathrm{C}$ among patients and to evaluate the epidemiology of these patients with malignancy reported at ACI, a Tertiary Care Cancer Hospital in Malwa region of Punjab, Bathinda.

\section{Aim}

1. To study the Epidemiology and Prevalence of hepatitis $\mathrm{C}$ among patients with malignancy reported at ACI, a Tertiary Care Cancer Hospital in Malwa region of Punjab, Bathinda.

2. Comparison of prevalence of HCV in patients from national data and oncology patients of our hospital.

\section{Materials and Methods}

The present study was carried out Advanced Cancer Institute Bathinda (Punjab), India. Data of the patients whose investigation was send for $\mathrm{HCV}$ and were HCV positive were collected for a period of 1 year 6months from 1.5.16 to 31.10.17. Relevant details regarding their demographic and geographical distribution was collected. Patients with positive anti$\mathrm{HCV}$ by using fourth generation kits enzyme immune assay were included, irrespective of age. Advanced 
Cancer institute being a Tertiary Care Cancer Hospital, these patients were mostly admitted with complaints of Cancer and not because of hepatitis $\mathrm{C}$ infection primarily. Patients who were not the residents of Punjab were also included.

All the specimens were screened using rapid immunochromatographic assays for $\mathrm{HCV}$ antibodies using TRI-DOT (J.Mitra \& Co.) respectively. The HCV TRI-DOT is a fourth generation assay for detecting antibodies against $\mathrm{HCV}$.

This 4th Generation HCV TRI-DOT is a rapid, visual, sensitive and qualitative in vitro diagnostic test for the detection of antibodies to Hepatitis C Virus in human serum or plasma with increased sensitivity for core and NS3 antibodies using a unique combination of modified HCV antigens. They are for the putative core (structural), protease/helicase NS3 (non-structural), NS4 (non-structural) and replicase NS5 (non-structural) regions of the virus in the form of two test dots "T1" \& "T2" to provide a highly sensitive and specific diagnostic test. All the tests were performed in accordance with the manufacturer's instructions with adequate controls. The data was statistically analysed.

\section{Discussion}

Significant association has been seen between $\mathrm{HCV} \&$ cancer, risk of cancer increases in patients with Hepatitis $\mathrm{C}$ virus infection and in turn Cancer puts extra ordinary challenges to the management \& treatment of $\mathrm{HCV}$. Prevalence of HCV infection in cancer patients ranges from $1.5 \%$ to $32 \%$ as reported by other authors. ${ }^{3-}$ 6 The present study, was undertaken to know the prevalence, epidemiological, demographic and geographical distribution of $\mathrm{HCV}$ in cancer patients reported at ACI, Bathinda. Prevalence of $\mathrm{HCV}$ infection in Punjab is high (3.5\%- 7\%) as compared to national statics (1\%) in India.

In our study, the Sero prevalence of HCV in cancer patients was $6.6 \%$ (chart 1).Whereas, prevalence of $\mathrm{HCV}$ in cancer as reported ranges from $1.5 \%$ to $32 \%$ $[3,4,5,6]$. In a another study done the by Malaguernera et al. ${ }^{8}$ on elderly cancer patients, $36 \%$ were reported positive for HCV antibodies. Regarding the sex distribution, in our previous study on investigation of HCV which was done in Department of Microbiology, GGSMCH, Faridkot we have reported that the prevalence of $\mathrm{HCV}$ in men is almost twice of the women, ${ }^{9}$ in another population based study done in Mullanpur (district Ludhiana), overall prevalence of $\mathrm{HCV}$ was found to be similar among males and females. ${ }^{10}$ In our study HCV was found to be more prevalent in females $(6.6 \%)$ as compared to males $(6.4 \%)$ (Chart 2). Thus, the risk of subsequent cancer was largely consistent irrespective of gender, suggesting that the observed association between HCV and cancers might be not due to the risk factors associated with $\mathrm{HCV}$, but due to $\mathrm{HCV}$ infection itself. In our study in males the risks for the cancers of the upper digestive tract, mandible, neck, oesophagus, and lung were elevated. Tobacco exposure and alcohol use explain somewhat of the excess risk. ${ }^{11}$ It is known that drug addicts because of sharing of needles have a very high risk of HCV infection, and these individuals are usually associated with excess alcohol drinking and cigarette smoking and tobacco consumption, which are the established causal factors for cancers in the lung, larynx, oral, larynx, and oesophagus. ${ }^{11}$ (Chart 5). In females 21 cases of carcinoma were reported out of which 12 were cases of carcinoma of breast, 2 of Endometrium, 1of Liver, 2 of Ovary, 1 of Oesophagus, 2 of Kidney, incidence of $\mathrm{Ca}$. breast was more probably in our rural area due to illiteracy and early sexual exposure as a result menarche sets up early. Early oestrogen release increases the chances of breast cancer. Thus, men usually have higher rates of lifetime drug-related risk behaviours, such as needle use and sharing, whereas women have higher rates of lifetime sexual risk behaviours. ${ }^{12}$ (Chart 5)

In majority of studies, ${ }^{11}$ and according to the literature review generally, the prevalence of $\mathrm{HCV}$ infection was highest in age group of 41-60 years followed by 21-40 years, the reason given is that these strata of age groups indulge in risky behaviour and practices such as unprotected sex and substance abuse.

In our study, maximum number of cases were in age group of 41-70 with 28 cases, 12 cases in age group of 50-60 years, followed by 8 cases in the age group of 60-70yrs and between age group of 20-40 years only 2 cases were reported. Maximum age going up to 94 years this is also contrary to the study done on general population (Chart 3), this might be due to the reason that patients must have acquired HCV either during the course of treatment and they are not primarily diagnosed first time in hospital. (Chart 4).

In our study predominant prevalence of $\mathrm{HCV}$ in cancer patients was in rural population(Chart 5) of subjects which was in adherence with the studies done by other authors and most likely reason is due to lack of awareness, improper health care facilities, faith in quacks \& drug abuse.

\section{Conclusion}

All the patients who were reported positive for $\mathrm{HCV}$ had underwent treatment of cancer and HCV according to national guidelines. Prevalence of HCV is $6.6 \%$ in our study which is not as high as reported by others. But things which need to be mentioned are, as maximum number of patients reported from rural background. These patients are very apprehensive to report to hospital and get themselves examined. So, the message is very loud and clear that either medical services especially in our rural areas need to be strengthened and practitioners sitting in rural population need to be educated to timely refer them to the higher centres or to look into traditional Indian system of medicine in which rural population have faith. 
Preventive aspects with the strengthening of AYUSH systems should be explored. The collaborative research should aim at developing traditional medicine as adjuvant therapy for cancer treatment and setting up a 'Centre of Integrative Oncology' for collaborating in areas of cancer prevention, research and care. Modern medicine, might not be enough to meet health needs of the society ailing with this dreaded disease.

As maximum number of cases are in females with Carcinoma of Breast urge the need to educate females regarding healthy sexual practices \& lifestyle modifications that could lower the incidence of cancer.

One patient who was reported $\mathrm{HCV}$ positive at 94yrs, suggests that patients might have acquired $\mathrm{HCV}$ either during the course of treatment. We need to reconsider about the sensitivity of testing systems for $\mathrm{HCV}$ in elderly cancer patients.

Our study was conducted for 1 year \& 6 months. By increasing the sample volume or duration we could have reached to more conclusive findings. This study can provide foundation to carry out larger multi centeric studies and act as eye opener in future research on this issue. Following AYUSH system of medicine, educating general population and guidance regarding healthy life style changes do have a major role to play.

\section{References}

1. National Institutes of Health Consensus Development Conference Statement: Management of hepatitis C 2002 , Gastroenterology. 2002 Dec;123(6):2082-99.

2. Virk S. Punjab leads in the Hepatitis $C$ cases. Times of India. 2009. May 19.(

https://timesofindia.indiatimes.com/defaultinterstitial_as. cms)

3. Fujii Y, Kaku K, Tanaka M, Yosizaki M, Kaneko T, Matumoto N. Hepatitis C virus infection in patients with leukemia. Am J Hematol. 1994;46:278-82.

4. Markovic S, Drozina G, Vovk M, Fidler-Jenko M. Reactivation of hepatitis B but not hepatitis C in patients with malignant lymphoma and immunosuppressive therapy. A prospective study in 305 patients. Hepatogastroenterology. 1999;46:2925-30.

5. Faggioli P, De Paschale M, Tocci A, Luoni M, Fava S, De Paoli A, Tosi A, Cassi E. Acute hepatic toxicity during cyclic chemotherapy in non Hodgkin's lymphoma. Haematologica. 1997;82:38-42.

6. Vento S, Cainelli F, Longhi MS. Reactivation of replication of hepatitis $B$ and $C$ viruses after immunosuppressive therapy: an unresolved issue. Lancet Oncol. 2002;3:333-40.

7. Uzun K, Alıc S, Özbay B, Gencer M, Irmak H. The incidence of hepatitis $\mathrm{C}$ virus in patients with lung cancer. Turkish Respiratory J. 2002;3:91-3.

8. Malaguarnera M, Gargante MP, Risino C, Ranno S, Berretta M, Cannizzaro MA, et al. Hepatitis $\mathrm{C}$ virus in elderly cancer patients. Eur J Int Med. 2006;17:325-9.

9. Arora D, Jindal N, Dang R, Kumar R. Rising Seroprevalence of HCV a Silent Killer-Emerging Problem. Int J Pharm Pharm Sci. 2011;3:57-9.

10. Sood A, Sarin SK, Midha V, Hissar S, Sood N, Bansal P, et al. Prevalence of hepatitis $C$ virus in a selected geographical area of northern India: A population based survey. Indian J Gastroenterol. 2012;31:232-6.
11. Swart A., Burns L., Mao L., Grulich A. E., Amin J., O'Connell D. L., et al. 2012. The importance of blood-borne viruses in elevated cancer risk among opioid-dependent people: a population-based cohort study. BMJ Open 2:e00175.

12. Butterfield M. I., Bosworth H. B., Meador K. G., Stechuchak K. M., Essock S. M., Osher F. C., et al. 2003. Gender differences in hepatitis $\mathrm{C}$ infection and risks among persons with severe mental illness. Psychiatric Serv. (Washington, DC) 54:848-53. 